\title{
Competition for EUS (a) EBUS-TBNA (b) video assisted thoracoscopy
}

A. M. Lennon ${ }^{1}$, R. C. Rintoul' ${ }^{2}$ I. D. Penman ${ }^{1}$

${ }^{1}$ Western General Hospital, Edinburgh, UK

2 Papworth Hospital, Cambridge, UK

\section{Introduction}

Mediastinal lymph node enlargement occurs in up to $38 \%$ of NSCLC at diagnosis [1]. The identification of cancer spread to the mediastinum, either as direct tumour invasion or as lymph node metastases, is critical as this not only determines prognosis but also treatment options. Stage I and II disease, where there is no evidence of spread outside the lung, is treated by surgical resection, while patients with low volume ipsilateral mediastinal lymph node metastases (stage IIIA) may be offered induction chemotherapy followed by resection. Chemotherapy/radiotherapy alone is reserved for patients with contralateral mediastinal or distant metastases (stage IIIB or IV).

\section{Non-invasive imaging}

Computed tomography (CT) allows assessment of the primary lesion and can also identify mediastinal lymph nodes and distant metastases in the liver or adrenals. The sensitivity of CT for detecting mediastinal lymph node involvement is very much dependent on the size of the lymph nodes with an overall sensitivity of $60 \%$ and specificity of $81 \%$ [2]. Studies have also shown that 'normal sized' nodes (i.e. short axis diameter less than $1 \mathrm{~cm}$ ) on CT harbour malignancy in $22 \%$ to $44 \%$ of cases $[3,4]$.

Positron emission tomography (PET) with 18-fluoro-2-deoxyflucose (FDG) has been reported to be more sensitive than CT at detecting both local and distant metastases with a sensitivity and specificity of $84 \%$ and $89 \%$ respectively reported in a recent meta analysis [2]. Data from individual trials, however, have been conflicting. One study concluded that addition of PET to a conventional staging work-up prevented unnecessary surgery in one-fifth of patients with potentially resectable NSCLC [5], while two larger studies failed to report an overall decrease in the thoracotomy rate [6,7]. Further large scale, prospective studies are required to clarify the role of PET scanning in NSCLC staging.

\section{Minimally invasive techniques}

Given the problems with non-invasive imaging, tissue sampling of suspicious lymph nodes has become increasingly important. Bronchoscopy with transbronchial lymph node aspiration (TBNA) can be performed in the outpatient setting using conscious sedation. This is a 'blind' procedure and is usually restricted to large

Correspondence: Dr. Ian D. Penman · Consultant Gastroenterologist · Western General Hospital · Edinburgh · EH4 2XU · UK · Phone: +44 1315371758 · Fax: +44131537 $1007 \cdot$ E-mail: ian.penman@luht.scot.nhs.uk 
subcarinal lymph nodes, with reported sensitivities varying from $38 \%$ to $89 \%$ reflecting the operator dependency of this approach $[8,9]$.

Cervical mediastinoscopy provides access to the left and right paratracheal lymph nodes (levels 2R, 4R, 2L, 4L) and sometimes the upper anterior subcarinal lymph nodes (level 7). Access to the aortopulmonary (AP) window (level 5) is limited by the aorta and the left main stem bronchus. Anterior or parasternal mediastinotomy also allows access to the AP window, pre-aortic lymph nodes (level 6) and subaortic lymph nodes. Mediastinoscopy requires a general anaesthetic, and has a complication rate of 1 to $3 \%$ [10] and up to $10 \%$ of patients with a negative mediastinoscopy, ultimately still undergo an exploratory thoracotomy without resection of the tumour [11].

Endoscopic ultrasound with FNA (EUS-FNA) offers a minimally invasive method of examining the posterior and inferior mediastinal lymph node stations and is safe, with reported complication rates of $<0.5 \%$ [12-14]. It is highly accurate for detecting nodal metastases, a recent study by Caddy et al demonstrating $92 \%$ sensitivity and $100 \%$ specificity in diagnosing mediastinal malignancy in 52 consecutive patients, findings corroborated in other studies $[15,16]$. The accuracy of EUS-FNA has been compared with other modalities including CT and PET. EUS has been shown to be more accurate than $\mathrm{CT}$ in identifying malignant mediastinal lymph nodes, including those with 'normal sized' nodes on CT [17 - 19]. EUS-FNA has also been compared with PET, again with superior sensitivity [20] and specificity [4].

One comparative study of transbronchial needle aspiration (TBNA) with EUS-FNA has shown that EUS-FNA has a higher diagnostic accuracy in mediastinal staging of lung cancer [21], while another has shown that by combining TBNA and rapid onsite cytopathologic evaluation with same day EUS-FNA if TBNA is negative [22] provides a diagnostic yield of $90 \%$. In patients in whom TBNA are negative samples are negative, subsequent EUS-FNA is often useful, with a reported sensitivity of $96 \%$ [12].

To date, in many centres the gold standard for identifying malignant mediastinal lymph nodes has been mediastinoscopy. Recent prospective studies randomly assigned patients to either conventional workup (i.e. mediastinoscopy and subsequent thoracotomy) or EUS-FNA [23]. $9 \%$ of the patients in the EUSFNA underwent a futile thoracotomy compared with $25 \%$ in the conventional workup group. When Eloubeidi et al compared EUS-FNA with mediastinoscopy, they found that $37.1 \%$ of patients who had a negative mediastinoscopy had malignant lymph nodes by EUS-FNA [24]. Another study found that EUSFNA identified more patients with tumour invasion or lymph node metastases compared with mediastinoscopy ( $28 \%$ versus $20 \%$, with a combination of both procedures identifying malignancy in $36 \% .16 \%$ of thoracotomies could have been avoided by using EUS-FNA in addition to mediastinoscopy [25]. The cost effectiveness of EUS-FNA was examined by Kramer et al. [26] who demonstrated that the addition of EUS-FNA to conventional lung cancer staging reduces the staging costs by $40 \%$ per patient, mainly as a result of fewer surgical staging procedures. Eloubeidi et al. have also shown that EUS-FNA is cost effective, with an average cost saving of $\$ 11,033$ per patient if EUS-FNA is used ini- tially rather than mediastinoscopy [24]. The main limitation of EUS-FNA is its inability to visualise stations anterior and superior to the trachea or main bronchi [27]. This can be overcome by combining it with alternative approaches such as mediastinoscopy or endobronchial ultrasound (EBUS).

\section{Endobronchial ulltrasound (EBUS)}

Endobronchial ultrasound probes were first developed to evaluate the depth of invasion of malignant tumours in the central and peripheral bronchi as well as for evaluation of lymph nodes located in the mediastinum in patients with lung cancer. Initially these were radial scanning catheter probes passed through the instrument channel of a bronchoscope and provided images of the wall layers of major airways and tumour invasion but had limited depth of penetration and nodes could not be sampled. Recently, a convex array probe has been introduced (Olympus BF-UC260F-OL8, Olympus Medical Company, Tokyo, Japan) which has a fine-needle aspiration biopsy facility (Fig. 1). The instrument is similar to a standard videobronchoscope, with an outer diameter of $6.9 \mathrm{~mm}$, a $2.0 \mathrm{~mm}$ instrument channel and $30^{\circ}$ oblique forward viewing optics. An electronic convex array ultrasound transducer is mounted at the distal tip and covered by a water inflatable balloon sheath. Scanning is performed at $7.5 \mathrm{MHz}$ and allows a penetration of up to $50 \mathrm{~mm}$. Image processing is performed by an Olympus ultrasound processor (EU-C2000).

\section{EBUS procedure}

EBUS is minimally invasive and can either be performed under conscious sedation [28] or under a general anaesthetic [29], often at the same time as standard bronchoscopic evaluation. The probe is passed through the mouth and vocal cords to the main carina, the balloon is partially inflated with water $(0.1-0.2 \mathrm{mls})$ and the regional lymph node stations of the middle mediastinum and hila (stations 2, 3, 4, 7 and 10 and sometimes 11) are systematically imaged and measured (short axis diameter) during slow withdrawal and rotation of the transducer.

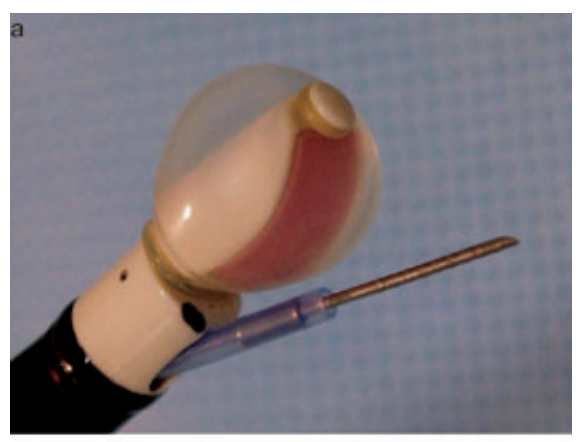

Fig. 1 (a) Convex array EBUS-FNA instrument (Olympus BF-UC260F-OL8) with 22 gauge needle. (b) with standard curved linear array instrument for EUS-FNA (Olympus GIF-UC 240P) for comparison.

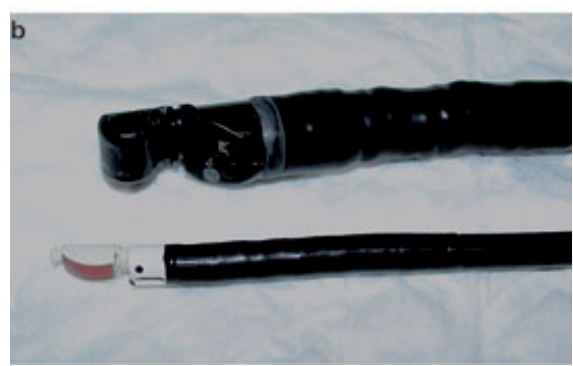




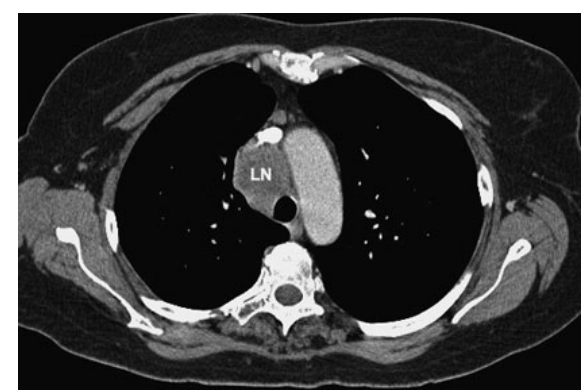

Fig. 2 Large right paratracheal (level 4R) lymph node (LN), accessible by EBUS-TBNA but not by EUS-FNA.

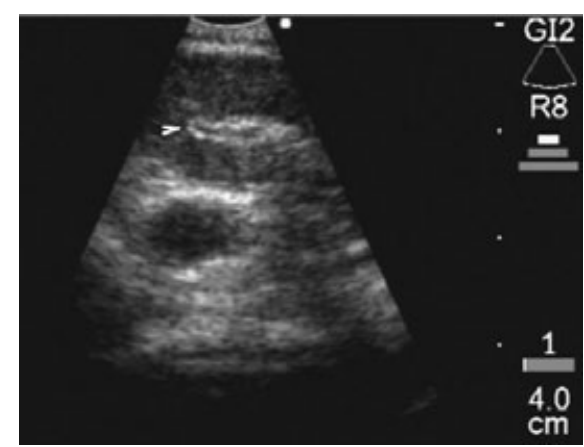

Fig. 3 EBUS image of benign reactive lymph node. Note the echo rich centre (arrow).

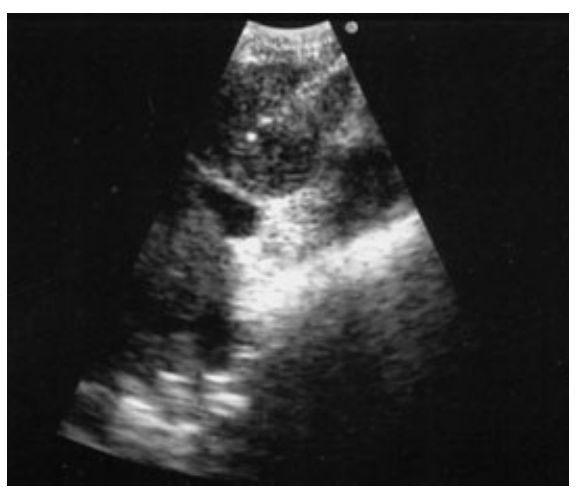

Fig. 4 EBUS-TBNA. The needle tip is clearly visible in the lymph node. Cytology confirmed nonsmall cell carcinoma.

Fine needle aspiration is performed using a dedicated 22 gauge needle passed through the airway wall and into lymph nodes under real-time ultrasound control. On occasion, cartilage rings prevent needle puncture, in which case the bronchoscope is moved a few millimetres cranially or caudally and repeat puncture performed. Aspirated material is processed in an identical manner to EUS-FNA. The optimum number of passes required in the absence of on-site cytology remains to be determined but in our experience 3 to 4 passes is associated with $90 \%$ sensitivity (unpublished data). With experience the procedure can be completed in approximately 30 minutes, is generally well tolerated and safe with minimal or no complications.

\section{EBUS resullts}

EBUS-TBNA has been used to stage nearly 200 patients in published papers [30-34]. None of the case series reported any complications, with a sensitivity for malignancy of $85 \%$ to $100 \%$ and specificity of $100 \%$ reported. Vilmann et al. have shown that EUSFNA with EBUS-TBNA are complementary, with a combination of the two giving $100 \%$ accuracy in their series of 31 patients [34]. Thus the combination of EUS and EBUS may offer more comprehensive access to the mediastinal and hilar lymph nodes than is currently available with mediastinoscopy, which is confined to the middle mediastinum. To date there are no comparisons of
EUS/EBUS versus mediastinoscopy or EUS/EBUS with VATS. A combination of EUS-FNA and EBUS could potentially minimise the need for surgical staging procedures and studies of this 'medical mediastinoscopy' approach compared to more invasive techniques are eagerly awaited. The two techniques visualise different mediastinal stations, are therefore truly complimentary and should not be regarded as competitors. EBUS-TBNA, however, is still in its infancy and questions remain to be answered. Larger case series are needed and data published to date are from expert centres and may not be reproduced as the technique rolls out into wider practice.

\section{Video assisted thoracoscopic surgery (VATS)}

While there is a significant literature regarding VATS and oesophageal cancer staging, there is a paucity of data relating to lung cancer, despite its recent resurgence in popularity due to improved video optics and thoracoscopic instrumentation. VATS is performed through one or more access ports in the intercostal spaces, thus limiting surgical trauma and postoperative pain associated with thoracotomy [35]. It provides a view of the ipsilateral hemithorax, hilum and paratracheal lymph nodes. In the right hemithorax the paratracheal lymph nodes (level 4R and 2R) can be visualised and biopsied. In the left hemithorax, the preaortic (level 6) and subaortic (level 5) lymph nodes can be seen. Several studies have shown the possibility of performing a final staging and surgical evaluation of lung cancer resectability $[36,37]$ as well as endoscopic lobectomy [38]. VATS presents some advantages over open surgery with less pain, smaller incisions, fewer and less serious postoperative complications and a shorter hospital stay [39]. It is, however, an invasive procedure, requiring a general anaesthetic, 1-3 days in hospital and has rarely been associated with tumour seeding in the extraction port $[40,41]$. As mentioned above, there are no published data comparing VATS with either EUS or EBUS.

\section{Conclusions}

The techniques available for staging NSCLC have increased hugely in recent years with a greater role for minimally invasive procedures such as EUS-FNA, EBUS-TBNA and VATS. These appear to be safe and accurate in studies to date but much work remains to be done in order to define the optimum staging algorithm for patients with NSCLC. Such studies are essential if we are to provide accurate staging that informs prognosis, selection of therapies and, hopefully, translates into better patient outcomes.

\section{References}

${ }^{1}$ Dillemans B, Deneffe G, Vershakelen M et al. Value of computed tomography and mediastinoscopy in preoperative evaulation of mediastional nodes in non-small cell lung cancer. Eur J Cardiothorac Surg 1994 ; 9: $37-42$

2 Toloza EM, Harpole L, McCrory DC et al. Noninvasive staging of nonsmall cell lung cancer: a review of the current evidence. Chest 2003; 123: $137-146 S$

${ }^{3}$ Wallace M, Kennedy T, Durkalski V, Eloubeidi MA, Etamad R, Matsuda $\mathrm{K}$ et al. Randomized controlled trial of EUS-guided fine needle aspira- 
tion techniques for the detection of malignant lymphadenopathy. Gastrointest Endosc 2001 ; 54: 441 - 447

${ }^{4}$ Fritscher-Ravens A, Bohuslavizki KH, Brandt L, Bobrowski C et al. Mediastinal lymph node involvement in potentialy resectable lung cancer: comparison of CT, positron emission tomography, and endoscopic ultrasound with and without fine-needle aspiration. Chest 2003; 123: $442-451$

${ }^{5}$ van Tinteren H, Hoekstra OS, Smit EF, van den Bergh JH et al. Effectiveness of positron emission tomography in the preoperative assessment of patients with suspected non-small-cell lung cancer; the PLUS muticentre randomised trial. Lancet 2002; 359: 1388-1393

${ }^{6}$ Viney RC, Boyer MJ, King MT, Kenny PM et al. Randomised controlled trial of the role of positron emission tomography in the management of stage I and II non-small-cell lung cancer. J Clin Oncol 2004; 22: $2357-2362$

${ }^{7}$ Herder G. Traditional versus up-front 18FDG PET staging of non-small cell lung cancer: a Dutch co-operative randomized study (abstract). Proc Am Soc Clin Oncol 2004; 23: 615

${ }^{8}$ Schenk DA, Chambers SL, Derdak S, Komadina KH et al. Comparison of the Wang 19-gauge and 22-gauge needles in the mediastinal staging of lung cancer. Am Rev Respir Dis 1993; 147: 1251-1258

${ }^{9}$ Katis K, Inglesos E, Zachariadis E, Palamidas P et al. The role of transbronchial needle aspiration in the diagnosis of peripheral lung masses or nodules. Eur Respir J 1995 ; 8: 963 -966

${ }^{10}$ Luke WP, Peason FG, Todd TR et al. Prospective evaluation of mediastinoscopy for assessment of carcinoma of the lung. J Thorac Cardiovasc Surg 1986; 91: 53-56

${ }^{11}$ Shields TW. Surgical treatment of non-small-cell bronchial carcinoma in General thoracic surgery, S. TW, Editor 1994 Williams and Wilkins, New York: p. 1159-1169

${ }^{12}$ Fritscher-Ravens A, Soehendra N, Schirrow L, Parupudi VJ et al. Role of transoesophageal endosonography-guided fine-needle aspiration in the diagnosis of lung cancer. Chest 2000; 117: 339-345

${ }^{13}$ Annema J, Vesleic M, Rabe KF. Analysis of subcarinal lymph nodes in suspected non-small-cell lung cancer after a negative transbronchial needle aspiration - what's next? Respiration 2004; 71: 630-634

${ }^{14}$ Caddy G, Conron M, Wright G, Desmond P et al. The accuracy of EUSFNA in assessing mediastinal lymphadenopathy and staging patients with NSCLC. Eur Respir J $2005 ; 25$ : 410-415

${ }^{15}$ Caddy GCM, Wright G, Desmond P et al. The accuracy of EUS-FNA in assessing mediastinal lymphadenopathy and staging patients with NSCLC. Eur Respir J 2005 ; 25: 410-415

${ }^{16}$ Annema JT, V M, Veselic M, Voight P et al. Endoscopic ultrasoundguided fine-needle aspiration in the diagnosis and staging of lung cancer and its impact on surgical staging. J Clin Oncol 2005; 23: $8357-$ 8361

17 Wallace MB, Silvestri GA, Sahai AV, Hawes RH et al. Endoscopic ultrasound-guided fine needle aspiration for staging patients with carcinoma of the lung. Ann Thorac Surg 2001; 72: $1861-1867$

${ }^{18}$ Frossard JL, Amouyal P, Amouyal G, Palazzo L et al. Performance of endosonography-guided fine needle aspiration and biopsy in the diagnosis of pancreatic cystic lesions. Am J Gastroenterol 2003; 98: $1516-1524$

${ }^{19}$ Wallace MB, Ravenel J, Block MI, Fraig M et al. Endoscopic ultrasound in lung cancer patients with a normal mediastinum on computed tomography. Ann Thorac Surg 2004; 77: 1763 - 1768

${ }^{20}$ Eloubeidi MA, Cerfolio RJ, Chen VK, Desmond R et al. Endoscopic ultrasound-guided fine needle aspiration of mediastinal lymph node in patients with suspected lung cancer after positron emission tomography and computed tomography scans. Ann Thorac Surg 2005; 79: $263-$ 268

${ }^{21}$ Wiersema MJ, Edell ES, Midthun DE et al. Prospective comparison of transbronchial needle aspiration biopsy (TBNA) and endosonography-guided biopsy (EUS-FNA) of mediastinal lymph nodes in patients with know or suspected non-small cell lung cancer [abstract]. Gastroinest Endosc 2002; 55: 79

${ }^{22}$ Khoo K-L, Ho K-Y, Nilsson B, Lim TK. EUS-guided FNA immediately after unrevealing transbronchial needle aspiration in the evaluation of mediastinal lymphadenopathy: a prospective study. Gastrintest Endosc 2006 ; 63: $215-220$

${ }^{23}$ Larsen SS, Viemann P, Dirksen A, Clementsen P et al. Endoscopic ultrasound guided biopsy versus mediastinoscopy for analysis of paratracheal and subcarinal lymph nodes in lung cancer staging. Lung Cancer 2005; 48: $85-92$
${ }^{24}$ Eloubeidi MA, Tamhane A, Chen VK, Cerfolio RJ. Endoscopic ultrasound-guided fine-needle aspiration in patients with non small cell lung cancer and prior negative mediastinoscopy. Ann Thorac Surg 2005; 80: 1231 - 1239

${ }^{25}$ Annema J, Versteegh MI, Veselic M, Welker L et al. Endoscopic ultrasound added to mediastinoscopy for preoperative staging of patients with lung cancer. Jama 2005; 294: 931 - 936

${ }^{26}$ Kramer H, van Putten JW, Post WJ, van Dullemen HM et al. Oesophageal endoscopic ultrasound with fine needle aspiration improves and simplifies the staging of lung cancer. Thorax 2004; 59: 546-547

${ }^{27}$ Silvestri GA, Hoffman BJ, Bhutani MS et al. Endoscopic ultrasound with fine-needle aspiration in the diagnosis and staging of lung cancer. Ann Thorac Surg 1996; 61: 1441 - 1446

${ }^{28}$ Rintoul RC, Skwarski KM, Murchison JT, Hill A et al. Endoscopic and endobronchial ultrasound real-time fine-needle aspiration for staging of the mediastinum in lung cancer. Chest 2004; 126: 2020-2022

${ }^{29}$ Krasnik M, Vilmann P, Larsen SS, Jacobsen GK. Preliminary experience with a new method of endoscopic transbronchial real time ultrasound guided biopsy for diagnosis of mediastinal and hilar lesions. Thorax 2003; 58: $1083-1086$

${ }^{30}$ Yasufuku K, Chiyo M, Sekine Y, Chhajed PN, Shibuya K, lizasa T et al. Real-time endobronchial ultrasound-guided transbronchial needle aspiration of mediastinal and hilar lymph nodes. Chest 2004; 126 : $122-128$

${ }^{31}$ Rintoul RC, Skwarski KG, Murchison JT, Wallace WA et al. Endobronchial and endoscopic ultrasound-guided real-time fine-needle aspiration for mediastinal staging. Eur Respir J 2005 ; 25: 416-421

32 Yasufuku K, C M, Koh E, Moriya Yet al. Endobronchial ultrasound guided transbronchial needle aspiration for staging of lung cancer. Lung Cancer 2005; 50: 347 - 354

33 Vilmann P, Krasnik M, Larsen SS, Jacobsen GK et al. Transesophageal endoscopic ultrasound-guided fine-needle aspiration (EUS-FNA) and endobronchial ultrasound-guided needle aspiration (EBUS-TBNA) biopsy: a combined approach in the evaluation of mediastinal lesions. Endoscopy 2005; 37: $833-839$

${ }^{34}$ Mentzer SJ, Sugarbaker DJ. Thoracoscopy and video-assisted thoracic surgery, in Current techniques in laparoscopy. D.C. Brooks, Editor. 1994 Philadelphia:: p. $1-20$

${ }^{35}$ Roviaro G, Varoli F, Rebuffat C, Vergani C et al. Videothoracoscopic staging and treatment of lung cancer. Ann Thorac Surg 1995; 59: 971-974

${ }^{36}$ Sugarbaker DJ, Strauss GM. Advances in surgical staging and therapy of non-small-cell lung cancer. Semin Oncol 1993; 20: 163-72

37 Walker WS. VATS lobectomy: the Edinburgh experience. Semin Thorac Cardiovasc Surg 1998; 10: 291 - 299

${ }^{38}$ Loscertales J, Jimenez-Merchan R, Arenas-Linares C, Giron-Arjona JC et al. The use of videoassisted thoracic surgery in lung cancer. Evaluation of resectability in 296 patients and 71 pulmonary exeresis with radical lymphadenoectomy. Eur J Cardiothorac Surg 1997 ; 12: 892 - 897

${ }^{39}$ Fry WA, Siddiqui A, Pensler JM, Mostafavi H. Thoracoscopic implantation of cancer with a fatal outcome. Ann Thorac Surg 1995; 59: 42 - 45

${ }^{40}$ Walsh FL, Nesbitt JC. Tumor implants after thoracoscopic resection of a metastatic sarcoma. Ann Thorac Surg 1995; 59: 215-216 